\title{
Alejo Carpentier: La expresión de lo real maravilloso americano, a setenta años de una teoría
}

\author{
Andrés Oscar Lora Bombino ${ }^{1}$ \\ Facultad de Humanidades, Universidad Central Marta Abreu de Las Villas, Cuba \\ Roberto Garcés González ${ }^{2}$ \\ Facultad de Ciencias Sociales, Universidad Central Marta Abreu de Las Villas, Cuba
}

Resumen: Alejo Carpentier (1904-1980) constituye autor imprescindible en el ámbito latinoamericano, pues su obra en diversos géneros: novela, cuento, ensayos, periodismo, propicia un rico testimonio del proceso cultural cubano, latinoamericano y universal, superando cualquier marco en el que quiera ser encasillado. Hombre de formación cultural amplia, toda la creación carpenteriana está en función del proceso cultural del mundo y el rol que puede jugar en la transformación del hombre. Por tanto, Carpentier es un hombre de cultura para la cultura, conocedor del valor que puede tener para la realización plena de la humanidad a la cual dedica todo su imaginario creativo que se convierte en su razón de ser. Esa sólida cultura humanista, con un marcado interés por lo cubano y latinoamericano, lo llevan a la necesidad de exponer sus más universales valores como forma de reafirmación de una identidad latinoamericana. Lo anterior ratifica el valor de su pensamiento expresado en esa diversidad creadora que lo llevan, en 1949, después de un proceso de maduración creadora, a exponer su teoría de lo real maravilloso americano como esencial aporte a la cultura de Nuestra América. El pensamiento de Alejo Carpentier asimila lo mejor de la creación universal que hace síntesis para lograr la universalidad latinoamericana de manera integradora.

Palabras claves: Historia, identidad, Latinoamérica, lo real maravilloso americano.

Título: Alejo Carpentier: A expressão real maravilhoso americano, a setenta anos de uma teoria

Resumo: Alejo Carpentier (1904-1980) se constitui em autor essencial no âmbito da América Latina, pois sua obra em diversos gêneros: romances, contos, ensaios, periodismo, propicia um rico testemunho do processo cultural cubano, latino-americano e universal, ultrapassando qualquer tentativa de vinculação a este ou aquele gênero. Homem de ampla formação cultural, toda a criação carpenteriana está em função do processo cultural do mundo e do papel que pode desempenhar na transformação do homem. Portanto, Carpentier é um homem de cultura para a cultura, consciente do valor que pode ter para a plena realização da humanidade, à qual dedica todo o seu imaginário criativo que se converte em sua razão de ser. Essa sólida cultura humanística, com

\footnotetext{
${ }^{1}$ Doctor en Ciencias Filosóficas. Profesor Auxiliar. Departamento de Periodismo. Facultad de Humanidades, Universidad Central Marta Abreu de Las Villas, Cuba. Orcid: https://orcid.org/0000-0002-4217-6296

E-mail: alorab@uclv.edu.cu

2 Doctor en Ciencias Sociológicas. Profesor Titular. Centro de Estudios Comunitarios. Facultad de Ciencias Sociales, Universidad Central Marta Abreu de Las Villas, Cuba. Orcid: https://orcid.org/0000-0002-9993-3761 E-mail: rgarces@uclv.edu.cu
} 
acentuado interesse pelos cubanos e latino-americanos, levam-no à necessidade de expor seus mais universais valores como forma de reafirmação de uma identidade latino-americana. $O$ exposto acima ratifica o valor de seu pensamento expresso nessa diversidade criadora que o leva, em 1949, após um processo de amadurecimento criador, a expor sua teoria do real maravilhoso americano como aporte essencial à cultura de Nossa América. O pensamento de Alejo Carpentier assimila o melhor da criação universal que sintetiza para alcançar a universalidade latino-americana de maneira integradora.

Palavras-chave: História; identidade; América Latina; O real maravilhoso americano.

Title: Alejo Carpentier: The wonderful american expression of the real thing, to seventy years of a theory

Abstract: Alejo Carpentier (1904-1980) is an essential author in the Latin American context, since his work in different genres: novel, short story, essays, journalism, provides a rich testimony of the Cuban, Latin American and universal cultural process, surpassing any framework in the who wants to be typecast. Man of wide cultural formation, all carpenterian creation is a function of the cultural process of the world and the role that can play in the transformation of man. Therefore, Carpentier is a man of culture for culture, aware of the value it can have for the full realization of humanity to which he dedicates all his creative imagination that becomes his reason for being.

This solid humanist culture, with a marked interest in the Cuban and Latin American, leads him to the need to present his most universal values as a way of reaffirming a Latin American identity. The above-mentioned ratifies the value of its thought expressed in that creative diversity that you/they take it, in 1949, after a process of creative maturation, to expose its wonderful American theory of the real thing as essential it contributes to the culture of Our America. The thought of Alejo Carpentier assimilates the best of the universal creation that synthesizes to achieve the Latin American universality in an integrating way where.

Keywords: History, identity, Latin American, the real wonderful american.

\section{La formación de la teoría sobre lo real maravilloso americano}

El estudio del pensamiento carpenteriano y sus diferentes facetas, abre perspectivas de análisis y aborda diferentes aristas de su pensamiento. En el aspecto que todos coinciden, por su trascendencia aportativa, es que Alejo Carpentier es uno de los pilares más particulares e innovadores en torno al tema de lo real maravilloso americano. Esta teoría, en su amplia dimensión, continúa su enriquecimiento y reafirma a la vez los rasgos de identidad cultural de la región. Al respecto señala Rigoberto Pupo: "Es indiscutible que el descubrimiento de lo real maravilloso abre cauces heurísticos y hermenéuticos sustanciales al discurso carpenteriano y a su cosmovisión. Es más, vehicula caminos holísticos a sus discernimientos filosóficos y literarios" (PUPO, 2003, p. 68), criterios que amplían la visión del pensamiento carpenteriano, revelador de importantes facetas para el quehacer de la cultura latinoamericana. Es conocido, por los enriquecedores estudios cubanos y de otros países, que el principio de lo real maravilloso americano, como teoría madura, se encuentra plasmado en el prólogo de su novela El reino de este mundo. Esta es consecuencia de un 
viaje a Haití en 1943 que hará nacer, además de su novela, la base de su teoría.

El principio de lo real maravilloso americano es resultado de la praxis artística del autor y de su proceso de maduración ideo-estética anterior a 1949. Debe entenderse lo real maravilloso americano como hecho evolutivo consciente, meditado en un proceso cognoscitivo lógico, al que arriba después de análisis y búsquedas de los postulados esenciales que lo conforman, cuya máxima expresión será 1949, pero el mismo tiene un importante antes y después. Por eso, es de gran valor lo que afirma el investigador y periodista Leonardo Padura Fuentes "... en contra de la abrumadora mayoría de los críticos más o menos establecidos, hasta qué punto lo real maravilloso era un concepto en evolución, hasta qué punto era una realidad americana y a la vez una estética para reflejarla", (PADURA, 1994, p. 8).

Carpentier tuvo una temprana visión de América y de su porvenir afianzado en su necesidad de conocer su historia y la influencia del pensamiento martiano. La idea de lo real maravilloso se presenta en él desde una perspectiva lógica y teórica, que busca establecer históricamente las características del ámbito continental al mostrar las más visibles de estas relaciones de contextos singulares y conjuntivos palpables en obras iniciales como ÉcueYamba-Ó, (1933), e Historias de lunas, (1933). Estas obras genésicas reafirman lo real maravilloso como un proceso donde esta va tejiendo un desarrollo y enriqueciendo su quehacer creador. Desde un primer momento, cuando ejerce el periodismo en La Habana o en París, su pluma se pone en función del rescate, defensa y universalidad del patrimonio cultural del continente, reafirmado en sus estudios teóricos, obras periodísticas y de ficción buscando la universalidad de lo latinoamericano, cuya mayor expresión será la teoría de lo real maravilloso americano.

No escapa la creación carpenteriana a la mirada de diferentes pensadores latinoamericanos que encuentran en su obra una importante zona de análisis para el estudio, desde diversas visiones, de América Latina y el Caribe. Por eso Arturo Andrés Roig expresa que:

En 1949 Alejo Carpentier, con su novela El reino de este mundo, nos abrió al mundo de lo real maravilloso, una de las vetas de nuestro mundo, recreando el desconocido mundo haitiano del siglo XVIII, el que estalla en sus manos maestras en los diversos mundos de sus personajes; en otros escritores nuestros tomará presencia la cuestión de la ajenidad, de la división, de la orfandad en el mundo, en fin, de la trastocación de valores que hace del mundo un orden injusto y hasta repugnante, un orden desordenado. (ROIG, 2001, p. 2)

Desde muy joven sintió la necesidad de conocer a fondo las particularidades culturales de la tierra que lo acogió como un cubano más pues como afirma Rafael Rodríguez Beltrán (2017) había nacido en Lausana, Suiza en 1904. Esto facilitó una perspectiva temprana de esa cultura, unida a esa formación profunda que recibió en el hogar. Estos inicios, junto a su posterior preocupación por lo americano le lleva durante su estancia parisina a una lectura de todo lo que tiene que ver con América, desde Colón hasta sus 
contemporáneos, "Tenía la oscura intuición de que mi obra se iba a desarrollar aquí, que iba a ser profundamente americana. Creo que al cabo de los años me hice una idea de lo que era este continente" (subrayado nuestro), (CARPENTIER, 1977, p. 63) hecho promisorio de incalculable valor. Este estudio irá sedimentando su conocimiento de lo americano y sus posibilidades de plasmación en su posterior obra, de importantes inicios con sus Crónicas y É-cue-Yamba-Ó.

Carpentier posee constante preocupación porque lo americano produzca su salto definitivo y se inserte en el concierto universal de los pueblos, demostrando sus valores y esto no es casual. A partir de la segunda década del siglo XX el proceso agresivo norteamericano sobre América Latina ha continuado su proceso ascendente como corresponde a una línea política sistemática, que ya Martí había definido en el XIX y en Europa los aires del fascismo corrían turbulentos por el Viejo Continente. Con el desarrollo y evolución del concepto de lo real maravilloso y desde esa perspectiva, Carpentier reafirma argumentos que definen la importancia del sincretismo, del mestizaje y la transculturación cultural, el esclarecimiento, el sentimiento de marginalidad, la heterodoxia, el desfase entre la realidad y aquella utopía que a través de los siglos burla una posible cristalización en la realidad, principios que se asocian con la idea de sus contextos desarrollados teóricamente en años posteriores, pero que al igual que lo real maravilloso van marcando pautas desde sus creaciones iniciales.

Su proceso de creación y maduración artística, consciente y activa, generará un compromiso intelectual de suma importancia para reafirmar la visión carpenteriana de América y de su identidad cultural. Descubre las potencialidades inmanentes a la realidad latinoamericana, al concebir a América, su historia, sus hombres y su cultura, como una síntesis irrepetible y maravillosa de elementos insólitos en tiempo y espacio. El propósito, trabajar en la conciencia del lector, en su visión del mundo, estableciendo una estrecha relación entre lo político y lo ético. Su precepto “¿Pero qué es la historia de América toda sino una crónica de lo real maravilloso?", (CARPENTIER, 1984, p.79), es inicio y continuidad de un pensamiento renovador, desalienante y auténtico que interactúa con el ideario martiano e interpreta dialécticamente la historia americana, en el expresivo recurso del toma y daca porque:

Advirtió Carpentier, bajo las diversas influencias de su siglo, con el precedente necesario de la obra del Maestro, las múltiples facetas de nuestra realidad maravillosa. Realidad en la que intervienen nuestra identidad cultural mestiza, una naturaleza indomable, el heroísmo de nuestros hombres, conocidos o anónimos, un rico caudal mitológico y una historia propia. Lo que en Carpentier fue certeza [...], en Martí fue vislumbramiento, intuición (VÁZQUEZ, 2004, p. 37).

Y precisamente esa visión maravillosa de Nuestra América, empieza a manifestarla desde su acercamiento inicial a la cultura cubana y latinoamericana expresada en su periodismo, en su primera novela, en su vinculación al minorismo cubano, en la escritura de textos tan importantes como La música en Cuba (1946) y en la perfecta armonía integradora 
de lo hispano y lo africano que se expresa en la música, en las danzas, en los rituales religiosos afrocubanos. En los procesos de la transculturación del ajiaco cubano, paradigma del pensamiento de Ortiz con el cual coincide, están las bases de lo real maravilloso.

El contexto histórico donde se desarrolla favorece el proceso evolutivo de su teoría. Su vínculo al minorismo y en general a toda la intelectualidad de la época, son decisivos para este inicio, preocupación y desarrollo de su teoría que no solo tiene mirada para lo cubano, también la pintura mexicana de Rivera y Orozco, la música del brasileño Villalobos y en sentido general todo el arte nuevo con valor, es objeto de interés del joven Alejo Carpentier. Los trabajos escritos a su llegada a París, muestran a un intelectual joven ya preocupado por los destinos culturales de Latinoamérica. Desde París, en carta a Jorge Mañach de 1930 dice, con gran sentido del humor criollo:

América me resulta mucho más interesante desde que me encuentro de este lado del charco grande. Algunas cosas de Cuba, de las que "tiramos a relajo", porque pasamos cotidianamente sobre ellas calzando los coturnos de la costumbre, han cobrado un relieve formidable ante mis ojos, desde que estoy aquí. El otro día, por ejemplo, he podido descubrir que el simbolismo sexual de la Charada China concuerda punto por punto con el simbolismo sexual-onírico de Freud. ¿Freud habrá ido a buscar los fundamentos de su teoría en China? (Citado por CAIRO 198485, pp. 396-397).

Experiencia parisina que posibilitó certificar la trascendencia de la concepción de la transculturación a nivel universal. La producción pictórica, musical o literaria es objeto de su mirada donde encuentra el carácter, temperamento y esencias, de un pueblo consolidado ya, culturalmente. El escritor entiende la necesidad de construir la imagen del continente y del Caribe desde una perspectiva americanista, no europeísta, a partir de una estética cuya primera idea esencial es el reconocimiento pleno de la americanidad. Todo este recorrido irá conformando su quehacer en función de lo real maravilloso americano. En 1946 en su ensayo La música en Cuba dirá:

\begin{abstract}
La presencia de ritmos, danzas, ritos, elementos plásticos tradicionales que habían sido postergados durante demasiado tiempo en virtud de prejuicios absurdos, abría un campo de acción inmediata, que ofrecía posibilidades de luchar por cosas mucho más interesantes que una partitura atonal o un cuadro cubista. Los que ya conocían la partitura de La consagración de la primavera - gran bandera revolucionaria de entonces - comenzaban a advertir, con razón, que había, en Regla, del otro lado de la bahía, ritmos tan complejos e interesantes como los que Stravinsky había creado para evocar los juegos de la Rusia pagana. [...]. Súbitamente, el negro se hizo el eje de todas las miradas [...] se iba con unción a los juramentos ñáñigos, haciéndose el elogio de la danza del diablito. Así nació la tendencia afrocubanista, que durante más de diez años alimentaria poemas, novelas, estudios folklóricos y sociológicos (CARPENTIER, 1979, pp. 243-244).
\end{abstract}

Esto viene a confirmar, en Carpentier, la interrelación entre lo universal y particular latinoamericano como concreción de lo universal concreto-situado, y a su vez, dentro de esta misma lógica, lo caribeño latino inserto en lo latinoamericano. Este pensamiento de transculturación referido a la música explicitado por Carpentier fue especificado por 
Fernando Ortiz, en profundización de su teoría, al escribir en 1952 el ensayo La transculturación blanca de los tambores de los negros, aquí argumentó:

\begin{abstract}
la influencia rítmica de los negros se hace tan irresistible que, no pudiendo transmitir sus prodigiosos tambores africanos a los blancos [su influencia abierta] porque tal transculturación estaba impedida por los convencionalismos sociales, se desquita de tal impedimento llevando sus impulsos rítmicos a las técnicas de ciertos populares instrumentos de cuerdas y reforzando los demás medios de ritmación ya conocidos. En Andalucía, no sólo con las palmas, el taconeo y las castañuelas, sino hasta con las cuerdas y las cajas de guitarras se hace música percutiva. En Cuba, el guayo no sólo se raspa sino que se golpea, se tamborean taburetes y cajones, se ritma el chaqui-charaqui de las chancletas como dos maracas, y se inventa la clave. Hasta el contrabajo y el piano a veces sirven como tambores (ORTIZ, 1991, p. 196).
\end{abstract}

Y añadió: "por la influencia de América, que lleva por toda Europa los bailes afroamericanos, el jazz, la machicha, la samba, el tango, la rumba, el son, la conga, el mambo, etcétera", (ORTIZ, 1991, p. 196). Hecho explicado por Carpentier, como se reveló, en La música en Cuba de 1946, por lo que puede sostenerse que hay un toma y daca entre los diferentes investigadores cubanos acerca de la contribución antillano-latinoamericano a la cultura universal, sobre todo en este caso particular del aporte etnocultural africano y caribeño.

Asimismo, desde París, mantiene una constante comunicación con intelectuales cubanos como Jorge Mañach, a quien pregunta si ha leído los capítulos de su primera novela, aparecidos en Imán, y donde reafirma la necesidad de tener presente los cambios que se van produciendo, la de abandonar viejos cánones, la búsqueda de misterios que encierra la vida cotidiana, descubrir esos hechos, presentes en cada región donde el latifundio y la modernidad han ido sustituyendo el pasado colonial pero subsistiendo todavía esas particularidades tan latinoamericanas.

Todo ese ideal tiene una raíz real maravillosa. Se ha dado cuenta del fenómeno que representa América Latina y ha comenzado a plasmarlo en una obra como É-Cue.... La visión no se limita solo al aporte identitario que significa el componente africano. Su perspectiva va más allá, enfatiza la importancia de lo indígena, establece analogías interculturales de civilizaciones de la antigüedad clásica con las pre-colombinas. Por ello en sus Crónicas de 1948, afirma "América reclama su lugar dentro de la universal unidad de los mitos, demasiado analizados en función exclusiva de sus raíces semíticas o mediterráneas", (CARPENTIER, 1993, p. 262). No solo reclama el justo lugar de lo americano latino en el concierto de la cultura universal, sino también se deduce una crítica al eurocentrismo. Establece así un elemento clave; entender en qué medida esta forma de hacer de América Latina es una forma expresiva de una cultura de resistencia para alejarse del sociologismo positivista de la literatura cubana de esos tiempos. A partir de estos criterios, recrea los desajustes cronológicos de América, recoge leyendas y mitos anteriores al descubrimiento y los revaloriza y recontextualiza para darles nuevas connotaciones, criticando ese eurocentrismo que intenta por cualquier medio minimizar lo no europeo. Busca nuevas 
esencias más allá de lo aparentemente fenoménico de lo real-aparencial, encontrando una nueva y fundamentada visión de la realidad latinoamericana.

Darle un carácter universal a lo americano, posibilita elevar lo real maravilloso americano a similar categoría, como un universal concreto situado. Para ello, se necesita una sensibilidad, un deseo, una necesidad para plasmarlo en la creación artística. Para lograrlo era vital evadir el localismo, eliminar ese pensamiento metafísico. Por contrapartida, un pensamiento renovador consecuencia de un proceso evolutivo y Carpentier uno de sus principales exponentes, un hombre resumen de lo mejor de los valores de esa evolución latinoamericana capaz de entender la confianza martiana en la fuerza y potencialidad intelectual, estética y cultural de la "Madre América", para integrarla con sus valores a lo universal, reafirmando su identidad cultural.

Fue capaz de darse cuenta que alcanzar lo real maravilloso no basta solamente comprender el carácter múltiple, transculturado o mestizo de la cultura latinoamericana. Esto se demuestra, parcialmente, en su quehacer temprano, pues incluso en un texto solo publicado posteriormente a medias, titulado "El momento musical latinoamericano" de 1931, insiste Leonardo Padura Fuentes que:

Constituye un "momento" trascendente para el entendimiento de su concepción de la ontología, el arte y la historia americana que se concretaría después en la teoría de lo real maravilloso, que sin ser tratada aún bajo este rubro, ya asoma su formulación en este texto perdido de 1931 (PADURA, 1994, p. 43).

Idea que continuaría con acercamiento al mundo americano, en 1933, con Écue..., donde, a través del mundo mítico y mágico del negro cubano, expresa los valores de este sector vital de la nación cubana y latinoamericana. Su obra es consecuencia de esa mirada colectiva hacia ese componente de la nación cubana, coincidiendo en el tiempo, con estudios teóricos de Fernando Ortiz, con la música de Amadeo Roldán y Alejandro García Caturla, con la poesía de José Zacarías Tallet y Nicolás Guillén, siendo una constante en su devenir creador, transformándose en conciencia política.

Esta primera obra va reflejando y madurando el concepto carpenteriano. El mundo del negro cubano con su carga de leyendas, supersticiones y sincretismos, revela dialécticamente, un fenómeno inseparable de nuestra historia y cultura. La historia contada, donde se entremezclan los más disímiles aspectos, va demostrando las infinitas potencialidades de la cultura cubana y, por extensión, latinoamericana, aún no explotada como: la religión, la música, las leyendas, las supersticiones, partes indisolubles de su identidad. Por ello puede afirmarse que:

El mundo mítico-mágico del negro es un elemento que refuerza el carácter maravilloso de la realidad que nos trasmite el autor. Aparece en la obra el intenso proceso sincrético operado en Cuba, a través de la presencia de los cantos, bailes y ritos principales de los cultos de origen africano, ocupando un lugar importante las relaciones de equivalencia que se producen entre los complejos yoruba, bantú y católico (VÁZQUEZ, 1987, p. 25). 
Con la aprehensión de este mundo, va más allá de una visión epidérmica o "negrista", que supera cualquier visión romántica. Lo real maravilloso ofrece una imagen compleja y maravillosa de transculturación solo entendida completamente por los individuos que logran percibir las contradicciones, paradojas, y antagonismos de la vida cultural y política del continente como algo cotidiano, como síntesis conformadora de identidad.

El sincretismo transcultural religioso de su primera novela, no es moda transitoria. Estos cultos sincréticos influyen en la concepción del mundo de sus creyentes, en su modo de pensar y actuar, lleva a sus personajes, a sentirse débiles ante las fuerzas ocultas o a una creencia fiel en el babalao como personalidad suprema que influye en el decursar de la familia de Menegildo, personaje protagónico de Écue... manifestado en lo que puede parecer un absurdo eclecticismo para el europeo en esa abstracción de personalidades en contradicción, (Kardek, Lenin, Cristo, etc.), pero normal en Cuba, incluso en la actualidad. Para sus personajes, esas grandes personalidades entrecruzadas, trasmiten fortaleza y confianza, lo que se convierte en concepción maravillosa y a la vez inserción de lo universal situado. Esos elementos de la mitología cubana, una especie de parodia de textos bíblicos, establecen una notable semejanza con historias bíblicas como Noé y su Arca. Reconoce así la universalidad del mito y la validez de lo particular, demostrando que la realidad americana es más rica que cualquier invención imaginativa. Reafirmó que lo extraordinario o lo real maravilloso está ahí, al alcance de la mano, lo necesario, tener es capacidad para descubrirlo.

Establece en estas páginas iniciales, un concepto que no niega el valor de lo real maravilloso. En primer lugar estas formas de pensamiento religioso (cultos afrocubanos sincréticos) son una forma de expresión o resistencia a la penetración norteamericana y, en segundo lugar, el peligro que puede provocar un oscurantismo enajenante opuesto a la ciencia. Coincidimos con Rigoberto Pupo cuando afirma:

La pasión merodeante por la música, la arquitectura, el barroquismo como constante humana, las teorías de lo real maravilloso y de los contextos, visto en su totalidad orgánica y mediados por un realismo utópico sin límites, encauzan la concepción del mundo en relación con el cosmos humano de nuestro primer novelista de todos los tiempos. (PUPO, 2003, p. 72)

Dentro de esta concepción de buscar lo maravilloso en los rituales afrocubanos y descubrir su magia, están otros elementos no menos importantes de la cultura popular cubana, que para este autor tienen igualmente este carácter. El animismo como tradición popular, manifestado en Historia de Lunas, junto al sincretismo religioso, misas, contactos con brujos, espiritismo, que conforman un acabado cuadro de este mundo, no escapa a su visión "por su contenido esencialmente práctico presentes en cada rincón de la realidad circundante, contribuyen a la cabal definición de nuestra identidad al ser llevados a escala de obra artística", (CARPENTIER, 1987, p. 19). Desde esta época, insiste reiteradamente que el hombre del siglo XX, puede vivir con otros situados hasta el neolítico. En América hay una constante coexistencia de diferentes etapas históricas, parte esencial de lo real maravilloso 
americano y de su identidad cultural.

El regreso a Cuba, después de larga estancia en Europa, presupone una mirada nueva de su tierra. Resultan vital, para entender los antecedentes de lo real maravilloso americano, las Crónicas de Alejo Carpentier publicadas en Carteles en 1939 denominadas La Habana vista por un turista cubano. Reflejan las esencias iniciales de esta teoría, escritas muchas con fino humor. Por ejemplo en la denominada Hacia Cuba, describe como muchachas jóvenes hacen el viaje Nueva York-Habana para encontrar novio y contraer matrimonio en el viaje. Al respecto comenta:

\footnotetext{
Una de ellas, trigueña encantadora, bate un récord con vertiginosa rapidez: a las cuarenta y ocho horas de viaje, contrae matrimonio, en Nassau, con un mozo a quien no conocía en el momento de embarcarse. Marcha nupcial ejecutada por el jazz de a bordo. Pastel de bodas; ofrecido por el capitán. [...] Este matrimonio me enternece. Me enternece porque es la prueba más tangible que se ha presentado hasta ahora de que estamos en el Nuevo Continente...Porque en Europa, ningún hombre sería capaz de casarse con una muchacha (aunque fuese de una belleza prodigiosa) sin saber de antemano: si la muchacha trae dote, y a cuánto asciende esa dote, cuál es la situación económica de los padres de la muchacha [...] iQue ridículo me resultas a veces, oh Viejo Continente! (CARPENTIER, 1987, pp. 185-186)
}

La crónica establece las diferencias Europa-América exponiendo, más allá de los argumentos literarios expresados por el cronista, la razón histórica que legitima lo maravilloso como parte de nuestra cultura latinoamericana, vista en su idiosincrasia y características peculiares que escapan a los "códigos racionalistas" de la cultura europea, designando justamente esa realidad natural y cultural, como real y maravillosa. Alejo Carpentier percibe y enseña desde dentro del continente, la realidad de la tierra con mirada autóctona, fruto de mezclas de culturas, un conjunto de elementos diferentes, que forman la original esencia hibrida del continente.

En la nombrada Pinturas Populares, describe establecimientos de ventas de diferentes productos y encuentra en el Mercado Único de La Habana una pollería de nombre "El Escorial" a la que vuelve a hacer alusión en crónica posterior titulada Rótulos de La Habana. Al volver por "El Escorial" cubano nos dice Carpentier "Debajo del nombre ilustre del panteón de los reyes de España, había florecido un nuevo letrero HAY JUTIA AHUMADA", [sic], (CARPENTIER, 1987, p. 197). Con estas crónicas, reafirma nuestras esencias a la manera de los latinoamericanos que siempre han definido y defendido con vehemencia su cultura en el contexto occidental, creando un sentido y un método de conocimiento para esa realidad histórica, expresivas del ser latinoamericano. En estos pasos, no perdidos, iniciales de Carpentier por el mundo de lo real maravilloso, capitales para la comprensión de su teoría, es necesario tener presente la intuición cabal de la identidad cultural de nuestra América y la necesidad de eliminar todo vestigio localista o provinciano para inscribirla, en la cultura universal, siempre concreto situada, manifestada en su total adhesión a la problemática sociopolítica y cultural cubana y latinoamericana de la época. 
Desde este momento inicial, asume su tiempo histórico y su compromiso con lo mejor del pensamiento revolucionario latinoamericano y universal, apropiándose, teórica y artísticamente, de esta realidad en su doble condición de real y maravillosa, de raíces esencialmente humanistas y martianas. Su visión realista y maravillosa de nuestra cultura mestiza y sincrética, de nuestra naturaleza, donde coexisten los más disímiles elementos, será un aporte vital para entender nuestra identidad, en su más amplio sentido y su más acabada concepción de lo real maravilloso americano.

\section{Lo real maravilloso americano como expresión de identidad cultural}

La teoría de lo real maravilloso americano de Alejo Carpentier es un fenómeno de identidad cultural e ideo-estético a partir de la comprensión dialéctica, históricamente condicionada que hace el autor de esta área geográfica en el decursar de su obra, alcanzando su maduración, análisis y comprensión en 1949, después de múltiples procesos que no pueden pasarse por alto, para lograr una cabal visión de sus propósitos en torno a su descubrimiento de lo real maravilloso americano. Reafirmando así, que su obra hay que verla en un todo armónico, de línea ascendente de creación, buscando elevar a Latinoamérica y su cultura al concierto universal de los pueblos. En este sentido, es un culminar del más genuino pensamiento de la región y una de sus máximas expresiones en la defensa de su identidad cultural, tanto desde su aporte teórico como práctico literario.

No podemos obviar que existen dos postulaciones teóricas sobre lo real maravilloso americano en Carpentier. La primera en el Prólogo a El Reino de este mundo, que es la genésica, la que todo el mundo toma como punto de partida. Pero en sus Tientos y Diferencias de 1964, aunque utilizamos su edición de Ensayos (1984), hay una concepción más amplia que Carpentier nombra De lo real maravilloso americano, donde establece una especie de paneo por diferentes culturas: China, el Islam, la Unión Soviética, Praga, Nuestra América. La valoración de cada una de ellas es demostrar el valor de esa cultura particular y su importancia para la universalidad y así demostrar que lo real maravilloso no es privativo de América sino que es un fenómeno universal. Lo cual a nuestro modo de ver, no contradice para nada que en entrevista de 1977, ya escrito el texto señalado, expresara "lo real maravilloso, que yo defiendo, es lo real maravilloso nuestro, es el que encontramos al estado bruto, latente, omnipresente en todo lo latinoamericano. Los conquistadores vieron muy claramente el aspecto real maravilloso en las cosas de América" (Carpentier, 1985, p. 363) y por eso insiste en el asombro de Bernal Díaz del Castillo en Historia verdadera de la conquista de la Nueva España al observar la ciudad de Tenochtitlán. Este retorno constante a su teoría la va enriqueciendo y demuestra el pensamiento dialéctico que le acompaña siempre, pues esa aspiración carpenteriana de universalidad se manifiesta tempranamente cuando confiesa que: "A los doce años ya había leído a Plutarco, Anatole France y a Pio Baroja pero jugaba con niños yucatecos que entre si hablaban el maya y eran analfabetos" (CARPENTIER, 1985, p.363). 
La concepción de lo real maravilloso americano, junto a la de los contextos, como parte coimplicada de su teoría, son aportes principales al tema de la identidad cultural latinoamericana. En ambos presupuestos teóricos, sienta pautas de aportadores valores ideo-estéticos que enriquecen su creación personal, y agregan aspectos sustanciales para entender el proceso de creación filosófica y literaria en América Latina. ¿Por qué una teoría de lo real maravilloso americano? Porque es una concepción sistematizada sobre un objeto determinado, incluye una nomenclatura de términos, conceptos que tributan a un objeto teórico determinado, principios, etc. agregar otras posibles que posibilitan la definición cabal del hombre americano, su historia y su cultura. Con este criterio continuamos la línea de investigaciones realizadas por: Graziella Pogolotti, Leonardo Padura, Rigoberto Pupo, entre otros. Otros autores sustentan otros conceptos. Por ejemplo Ángel Rama sostiene que:

Lo real-maravilloso aparece entonces como una reformulación del exotismo que los latinoamericanos cultivaron para los europeos y para los habitantes de sus propias ciudades, - tan deliciosamente artificioso (y reparador espiritualmente) como las novelas pastoriles que se escribieron en el quinientos para el cenáculo cortesano de las ciudades italianas (RAMA, 2010, p. 236)

Respetamos el criterio pero no lo compartimos, pues nos parece niega toda la formulación, desarrollo y praxis de la tesis carpenteriana. Por su parte, Irlemar Chiampi, teórica brasileña, en (El realismo maravilloso, 1983), no comparte la concepción de América como tierra de lo real-maravilloso, prefiere calificar esta noción como - unidad cultural-partiendo de que Carpentier es un -interpretante del referente América- y por tanto no es necesario insistir en su valor de verdad o falsedad. Este concepto no tiene en cuenta, no es el único, la necesidad de ver la inseparable relación de toda la obra carpenteriana, no centrarse solo en la novela, sino ver el periodismo y sus ensayos también como medios para expresar ideas estéticas, filosóficas, criterios de valor, cuando Carpentier cambia su posición de periodista en entrevistado (1977) continua esta autora centrada solo en el prólogo de El Reino.... y olvida también el ensayo del 64 sobre el mismo tema. Al margen de esta discrepancia el texto señalado de Chiampi es uno de los análisis más completo y profundo sobre la teoría carpenteriana y clave para entender el devenir de la identidad cultural en el autor cubano.

A partir de la maduración de su teoría, se convierte en uno de los representantes más genuinos del movimiento renovador de la narrativa latinoamericana, al propiciar una asimilación artística del complejo mundo de la historia de nuestra América y sus destinos humanos, en los que la lucha por una autorrealización y ascenso del ser latinoamericano a escala humana y universal, en el cual el hombre sea capaz de realizarse plenamente, es parte esencial de su razón de ser, ya que como afirma Salvador Arias:

Carpentier es un escritor realista, inclusive sumamente apegado al documento histórico o al testimonio autobiográfico. Pero esta realidad está expresada a través de medios complejos, en los cuales la alusión culta se mezcla con la observación intuitiva y se depuran técnicas y recursos de múltiples escuelas y épocas literarias 
[...] que hace que las más complejas lucubraciones se conviertan en nervio vivo y palpitante, cuyos latidos se fusionan sólidamente al lector, más allá de vocablos, símbolos y aparentes artificios [...] si bien sus textos admiten varias lecturas, no por eso dejan de estar claramente orientados hacia un significado dominante, que se hace más evidente si tomamos sus obras como un todo (ARIAS, 1977, p. 8).

Los caminos investigativos trazados para conformar su reflexión cultural, constituye un todo abierto para seguirlo en su devenir histórico. La teoría de lo real maravilloso es proceso de concientización de un pensamiento en una lógica dialéctica de comprensión de la realidad cubana, caribeña, latinoamericana; y por consiguiente universal concreto-situada. Sus investigaciones, sumadas a sus viajes por el Orinoco y el Amazonas, ofrecieron ver numerosas nuevas posibilidades para enriquecer el pensamiento y la novelística latinoamericanas con ideas y enfoques renovadoras. Al respecto sostiene Rigoberto Pupo que:

El descubrimiento de lo real maravilloso, deviene teoría filosófico-literaria y método aprehensivo de la realidad latinoamericana y otras regiones de nuestro planeta con semejante especificidades. Es un modo particular de aprehender la realidad subjetivamente, sin caer en los brazos del subjetivismo. Un sentido cultural de asumir la realidad en su expresión sistémica, sin soslayar la complejidad de las mediaciones varias de naturaleza subjetiva y objetiva en que deviene el hombre en relación con su mundo o entorno individual y sociohistórico. Es en sí mismo la búsqueda de la identidad americana [latina], en su diversidad y riqueza expresiva, con espíritu de raíz y vocación ecuménica, (PUPO, 2003, p. 98).

Estas ideas permiten afirmar la clara comprensión del mundo carpenteriano. Su apreciación de este mundo permite explicitar su teoría con toda lógica de progresión y crecimiento. Contrapone esa realidad haitiana - por ampliación latinoamericana de sus obras-, a las pretendidas visiones maravillosas que intentaron brindar las literaturas del Viejo Continente, viejos esquemas europeos que perdieron ya su capacidad de asombro, quedando en una pobreza imaginativa como sostuvo Miguel de Unamuno. La utilización de repetidos cánones es tratada con visión irónica, pues carecen del verdadero valor reflexivo y novedoso, sencillamente porque se dedican a repetir fórmulas gastadas de visión epidérmica que nada pueden ofrecer a una nueva concepción de lo maravilloso, y menos en claves de realidad.

Como punto de partida hay que tener en cuenta lo manifestado por Carpentier al contraponer su concepción de lo real maravilloso con lo entendido por las academias y diccionarios. Afirmó que las definiciones académicas definen lo maravilloso como lo "extraordinario, excelente, admirable", en asociación con la noción de lo que debe ser "bello, hermoso, amable". Mientras en proceso de resemantización acotó que lo único que debe ser recordado de esas definiciones es lo "extraordinario" que posibilita lo insólito y rebasa los parámetros normales. Por eso subrayó: "debemos establecer una definición de lo maravilloso que no entrañe esta noción de que lo maravilloso es lo admirable porque es bello. Lo feo, lo deforme, lo terrible, también pueden ser maravilloso. Todo lo insólito es maravilloso" (CARPENTIER, 1984, p. 120). 
No obstante referir él mismo el enunciado citado como definición, en verdad solo es un rasgo de la misma, porque en diferentes ocasiones volverá sobre el concepto de lo real maravilloso americano. En Amberes, Bélgica (1977), al dictar una conferencia especificó:

\begin{abstract}
Consiste en hallar lo maravilloso de ciertas realidades latinoamericanas existentes y no en fabricarlas, porque el surrealismo -y esto fue lo que determinó la muerte del grupo- después de una magnífica trayectoria de cuarenta años, acabó por ser una fábrica de maravillas. Nosotros lo maravilloso lo tenemos al estado bruto, al estado puro, y ahí está definido lo real maravilloso. (El subrayado es nuestro). (CARPENTIER, 1987, p. 159)
\end{abstract}

Ante la pregunta de un estudiante belga, que intentaba cuestionar la concepción de lo real maravilloso americano, al referir que América Latina no tenía en esa década una realidad maravillosa, sino más bien de lo que podría llamarse "lo real horroroso", por la existencia de dictaduras militares, crisis económicas, etcétera, Carpentier respondió:

\begin{abstract}
Lo real horroroso de América Latina es tan realmente horroroso que se vuelve tan insólito como lo real maravilloso. Entonces, ¿cuál es la misión nuestra. Si el escritor latinoamericano tiene el don de revelar lo real maravilloso, si tiene el don de revelar lo maravilloso, el ciudadano que hay dentro de cada escritor latinoamericano debe combatir con todas sus fuerzas, como lo hacen millares y millares de intelectuales latinoamericanos, lo real horroroso. $Y$ en eso estamos empeñados muchos, y me jacto de que uno de ellos soy yo. (CARPENTIER, 1987, p. 159)
\end{abstract}

Una vez más puntualiza como componente de su teoría de lo real maravilloso, la naturaleza latinoamericana plural, pero también el todo de la sociedad y cultura existentes, la historia de la lucha por la libertad y liberación latinoamericana. No es casual que su teoría de lo real maravilloso la explicitara con El reino de este mundo donde abordó la lucha de los esclavos de origen africano contra el colonialismo francés, primera gesta emancipadora triunfante contra el colonialismo latino-europeo en Nuestra América.

Con estos criterios continúa perfilando y definiendo lo real maravilloso como manifestación de la identidad cultural latinoamericana. Lo real maravilloso tiene para él función vital, servir al hombre americano en su proceso emancipatorio que implica búsqueda de libertad e independencia. Cuando los personajes héroes de sus novelas, como Mackandal, se hace animal u objeto de la naturaleza no lo hace con el objetivo de huir o desertar, la transformación en héroe ejemplar se sustenta en acción colectivo-liberadora que tiene en la búsqueda del pasado, revitalizar la historia de África ahora en perspectiva latinoamericana, a la vez que dignificar el mito y acrecentar el valor de lucha ante la injusticia del opresor colonialista.

Esta idea es una regularidad, una línea transversal que recorre toda la concepción de lo real maravilloso carpenteriano, la cual cobra gran relevancia en un libro como El Recurso del método, de 1974, donde caracteriza a los dictadores y tiranos de América de todos los tiempos, con particular énfasis en los de esa época. Aquí revive al pícaro de la novela española y latinoamericana en la persona del dictador latinoamericano, pero con notable 
diferencia. El pícaro novelesco - Lázaro, Periquillo Sarniento, Pablos-, lucha por la supervivencia, de aquí su multiplicidad de oficios que ejecuta; mientras el pícaro dictador expresa su obstinado empeño de supervivencia en el mando opresor, perpetuándose en el cargo (Porfirio Díaz o Machado), a través de golpes de estado (Batista o Pinochet), usurpando poderes (Gómez) o dictadores impuestos por Estados Unidos como Victoriano Huerta, entre varios más. Así comparativamente expresó las diferencias entre unos y otros:

\begin{abstract}
No mataban a nadie. Fueron fuyeros [copia fiel del original, sic] y mentirosos, incultos y viciosos, pero jamás atentaron contra la vida humana. Los pícaros de América Latina, en cambio, fusilan centenares de hombres en sus estadios deportivos, es decir, pasan del gracioso plano de El lazarillo de Tormes al de Ubu-rey de Alfred Jarry y retrocediendo en la historia se sitúan en la noche de San Bartolomé y, de repente, declaran que prohibirán el estudio del marxismo en sus universidades, confundiendo (un error lo tiene cualquiera) El capital con La técnica del golpe de Estado, de Curzio Malaparte. Desde luego que son incapaces de entender que nunca fue El Capital un manual para la toma del poder en país alguno, sino lo que Michel Foucault señala como «la apertura de un campo epistemológico» [...]. La picaresca española es graciosa y ocurrente, la latinoamericana es trágica y sangrienta. De ahí que mi libro, empezando en buen humor y ritmo de sainete, se va volviendo dramático y duro a medida que avanza la acción (CARPENTIER, 1985, p. 207).
\end{abstract}

Visión del dictador latinoamericano que había perfilado en 1933 en su crónica Retrato de un dictador, dedicada a la figura de Gerardo Machado de triste recordación para Cuba, y en particular para el propio Carpentier. No puede haber dubitación posible que el tema de la emancipación humana latinoamericana, la lucha por la liberación y la libertad, tanto en su teoría como en la praxis narrativa confirma que esta es uno de los importantes contextos de lo real maravilloso americano y de su identidad cultural.

Al seguir los ítems y variables que el propio Carpentier dio en diferentes textos y ocasiones en torno a lo real maravilloso americano, se define como un concepto que caracteriza lo extraordinario que sobrepasa los límites imaginados más allá de lo común y lo normal en el orden socio-cultural, que presupone un todo abierto de oposiciones e interacciones articulantes de carácter heurístico como lo bello y lo feo, lo positivo y lo negativo, la imaginación y la reflexión, lo trágico y lo sublime, lo cotidiano y lo extraordinario, la filosofía y la cosmogonía, formas de lo cómico y lo grotesco, lo temporal y atemporal, lo mítico y lo real, lo humano y lo degradante, lo geográfico y las prácticas socio-culturales de hombres en diversos contextos concreto-situados. Por tal razón, al centrar lo real maravilloso en Nuestra América, en la amplia perspectiva antes referida, lo real maravilloso americano constituye una concreción de identidad cultural.

Desde esa perspectiva, la contraposición América-Europa es referida al contexto de las artes, en particular la pintura al expresar:

Cuando André Masson quiso dibujar la selva de la isla de Martinica [...] la maravillosa verdad del asunto devoró al pintor, dejándolo poco menos que impotente frente al papel en blanco... ¿Quién podría - según Carpentier - lograr 
una verdadera visión maravillosa de lo americano? Por supuesto un pintor de América... Y tuvo que ser un pintor de América, el cubano Wilfredo Lam, quien nos enseñara la magia de la vegetación tropical, la desenfrenada Creación de Formas [sic] de nuestra naturaleza - con todas sus metamorfosis y simbiosis - en cuadros monumentales de una expresión única en la pintura contemporánea. Ante la desconcertante pobreza imaginativa de un Tanguy, [...] que desde hace veinticinco años pinta las mismas larvas pétreas bajo el mismo cielo gris (CARPENTIER, 1992, p. 3-4).

En el manejo de su teoría, usa constantemente la contraposición para expresar el aquí-allá, como procedimiento de legitimar la identidad plural del continente latinoamericano y su ser, creando un sentido y una teoría de conocimiento para una realidad histórica. América Latina muestra no solo un paisaje maravilloso y desconocido, sino también creadores (pintores, narradores, músicos, filósofos) que con el espíritu renovador de la época, llevan lo nuestro más allá de las fronteras propias, alcanzar la universalidad, supremo fin del gesto creador carpenteriano. Por ello Irlemar Chiampi sostiene. "Lo real maravilloso está marcado por el intento de significar la identidad del continente americano (ya sea en su aspecto histórico, político, social, religioso o mítico), tomándolo como espacio privilegiado para las aventuras de sus héroes", (CHIAMPI, 1983, p.120). Sin que por esto niegue los valores universales de la cultura y ahí está su verdadero acierto. Corroborar lo nuestro, sin negar lo ajeno, es también importante. El sentido de oposición de espacios y valores tiene larga trayectoria en su obra y es un recurso de innegable valor a la hora de enfrentar un análisis que intenta demostrar su carácter aportador. Encontramos constantemente elementos contrapuestos (campo-ciudad en Écue- Yamba-Ó) AméricaÁfrica-Europa en El reino de este mundo, por solo citar dos, en el sentido de oposición de mundos geográficos palpables, presentando una noción de temporalidad y sentido de valor, que en cada caso, puede demostrar como en su espacio (campo, ciudad o continente) puede estar igualmente, la universalidad. La oposición espacial se da también en el sentido de los seres humanos (Menegildo, Ti Noel, Filomeno). Como seres oprimidos, enfrentan con dignidad totalizadora a sus opresores, en demostración de una capacidad humana que busca el camino pleno de la desenajenación y liberación del hombre. Reafirmará así su concepción del hombre, sujeta a giros notables, dinámicos y fluyentes, en continua reciprocidad con el curso de la historia.

En tal sentido de oposición, en todos los matices que quiera expresarse, intenta y logra exponer una tesis muy carpenteriana, inmersa en su gran objetivo de escritor; lo real maravilloso americano. La capacidad para encontrar nuevos contextos culturales en la América Nuestra, para definir su teoría y convertirse en soporte también de la identidad cultural latinoamericana, radica en saber encontrar las diferentes fusiones de Latinoamérica: histórico -social, étnica, lingüística, geográfica, que hace brotar otra realidad propia de esta parte del universo. A partir de un múltiple sincretismo no estrictamente étnico, sino también religioso, cultural, y hasta económico, en lo principal transculturado, fundamentación básica de lo real maravilloso. Estas ideas buscan similares objetivos: reafirmar la identidad cultural de Nuestra América. 
En contacto con esa América por descubrir todavía, va localizando elementos mágicos, a veces sin explicación "lógica" tradicional como inesperada alteración de una realidad que cada vez se revela más interesante. Esto lo lleva a expresar el concepto "lo maravilloso presupone una fe" que no está, en ciertos recursos utilizados por los europeos que en condición son ciertas "artimañas literarias". En Carpentier es diferente, porque significa sentido creador de un nuevo hecho histórico como un proceso cognitivo que comienza a conocer a fondo la realidad latinoamericana:

Contacto cotidiano con algo que pudiéramos llamar lo real maravilloso. Pisaba yo una tierra donde millares de hombres ansiosos de libertad creyeron en los poderes licantrópicos de Mackandal, a punto de que esa fe colectiva produjera un milagro el día de su ejecución [...] Había respirado la atmósfera creada por Henri Christophe, monarca de increíbles empeños, mucho más sorprendente que todos los reyes crueles inventados por los surrealistas [...] A cada paso hallaba lo real maravilloso. Pero pensaba, además, que esa presencia y vigencia de lo real maravilloso no era privilegio único de Haití, sino patrimonio de la América entera, donde todavía no se ha terminado de establecer, por ejemplo, un recuento de cosmogonías (CARPENTIER, 1992, p. 6).

El mérito de Alejo Carpentier consiste en descubrir que lo maravilloso como categoría, incluye al pueblo y lo popular, en sentido amplio, como fuente esencial y original, creando un universo determinado y racional donde los acontecimientos resultan naturales, posibles y lógicos. Lo maravilloso determina un mundo que recoge y asume los motivos y elementos sobrenaturales de lo popular, construyendo una historia. En lo fundamental, expresión de la vida de los hombres traducidos en: mestizaje, paisaje, personajes míticos que lucharon por la libertad, mitos que expresan identidad en sus varios contextos, de lo cual se desprenden importantes criterios.

En su teoría sobre lo real maravilloso americano generaliza y crea una categoría propia: toda acción o acontecimiento asombroso, todo portento insólito, todo lo inexplicable, todo aquello que produce un efecto sobrenatural de su esencia, lo establece como "maravilloso". Su concepción de lo real maravilloso resulta integradora porque su mirada del mundo latinoamericano posee una función social, con capacidad suficiente de generar comunicación pues, por ejemplo, mira la historia con otro sentido, lo que provoca enfrentamientos con sus lectores críticos y genera múltiples opiniones. Esto lleva a adquirir una función social e implícita, una crítica a la realidad, a la sociedad y a una ideología impuesta por siglos al hombre americano y a su contexto. Con esta visión explora el espacio de lo interior, enaltece la imaginación y la esperanza de salvación del hombre latinoamericano.

Otro de sus méritos es la capacidad para examinar el fecundo mestizaje de la región, que posibilita ese entramado característico del área americana conjugando armoniosamente paisaje físico y humano, cuyo producto artístico es algo real y maravilloso pues esa capacidad americana de no agotar su caudal de cosmogonías, al decir de Carpentier, descubre esa realidad presente a flor de tierra. Para él esta realidad es más rica que 
cualquier invención imaginaria. Lo poético y lo real maravilloso están a nuestro alrededor e influyen constantemente en la vida del ser americano, debido al profundo mestizaje, como proceso de transculturación que posee el continente, con el cual coincide plenamente. Corroboró una vez más el proceso de maduración de la teoría en el decursar de su obra porque el pensamiento carpenteriano vislumbra una visión de futuro y convierten su teoría en:

Gesto fundacional mítico, disidente, mestizo y afirmador de la diferencia, en ocasiones gesto abiertamente político. [...] en última instancia, un gesto profundamente descolonizador que convierte a nuestros escritores en antropólogos al revés, que desdeñan la otredad exótica para mirarse en su propio contexto cultural e histórico (el subrayado es nuestro). (LÓPEZ BARALT, 2005, p. 471)

En esta perspectiva de lo real maravilloso está presente la historia, aspecto a tener en cuenta, cuando valoramos su obra. Esto hace que ficción e historia se entrecrucen dialécticamente como esencia consustancial y vital en su obra. Sus historias son construidas a partir de documentaciones rigurosamente comprobadas, del uso exacto de fechas, cronologías y hasta nombres propios dejando que lo maravilloso fluya libremente como parte de una realidad estrictamente seguida en todos sus detalles. Al respecto, Virgilio López Lemus deja claramente definida la posición de este autor cuando afirma:

Carpentier, convencido marxista-leninista, tiene una más amplia y racional
comprensión de la circunstancia político-social que se refleja en su obra toda. Ello
es prueba fehaciente de que la ideología tiene papel esencial en el propio estilo del
artista y que las cuestiones que a primera vista pudieran parecer solo formales (uso
del vocablo idiomático, el estilo, el barroquismo del lenguaje), guardan franca
relación con la creación, con el hecho artístico mismo y con la base ideo-valorativa
de la realidad, fuente para la creación. (LÓPEZ LEMUS, 1984-85, p. 428)

Con el desarrollo de su teoría, fundamenta la necesidad que tiene América Latina de un nuevo enfoque cultural y artístico literario para alcanzar su más plena identidad, por eso su obra es portadora de un compromiso social plasmado en su visión como pensadornarrador de su tiempo, a lo que no es ajeno sus constantes declaraciones a favor de la Revolución Cubana y que no resulta vano destacar, por las variadas interpretaciones y consideraciones sobre su obra y forma de actuar, al valorar este aspecto, acertadamente José A. Portuondo afirmó: “Ha dado siempre, junto a la obra, su razón de ser, al lado de la práctica creadora, la teoría literaria y ha precisado [...] conceptos que lo hacen un auténtico maestro y guía de las letras hispánicas", (PORTUONDO, 1984, s/p).

Esa unidad es consustancial de la obra del cubano universal. Resaltó la importancia de valores autóctonos latinoamericanos, a la par de otras regiones del mundo y sus culturas. Encuentra en las crónicas de Bernal Díaz del Castillo, las fantásticas aventuras que narra Cervantes en El Quijote. A partir de este criterio prueba y demuestra por qué puede hablarse de que América Latina tiene valores para incorporar al concierto universal de los pueblos, y 
poder hablar de lo real maravilloso americano no solo como una teoría literaria, que por sí sola tiene un gran valor, pero la concibe de modo más amplio, como pensamiento teórico cultural y anti hegemónico, por ello Irlemar Chiampi afirma con justeza:

\footnotetext{
Haití y su historia como elaboración de una idea de América. Compendio de prodigios naturales, culturales e históricos. Con su concepto de lo real maravilloso Carpentier identifica una identidad cultural, cuyos rasgos de formación étnica e histórica son a tal punto extraños a los patrones racionales que se justifica predicar metafóricamente lo maravilloso de lo real, (el subrayado es nuestro). (CHIAMPI, 1983, p. 40)
}

Lo real maravilloso americano no está solo en esas realidades, aparentemente fantásticas, que pueden emular con la mente cervantina. De esa herencia de siglos, que a veces puede parecer absurda, surgieron escritores y pensadores como José Martí, científicos como Carlos J. Finlay o poetas como Rubén Darío. Ejemplos probatorios de que la cultura y el hombre americanos son aportadores no solo de hechos que pudieran enmarcarse dentro de un fenómeno puramente fantástico, sino que América crea hombres de un pensamiento que sobrepasa los marcos regionales para aportar juicios y criterios culturales, estéticos y filosóficos tenidos en cuenta al otro lado del océano, como son los casos de José Martí, Rubén Darío, Octavio Paz, Jorge Luis Borges, Leopoldo Zea o Enrique Dussel.

Cuando se penetra en la historia latinoamericana encontramos rasgos de esencia maravillosa. Piénsese en la acción de Benito Juárez contra la ocupación francesa; la figura de Juana de Azurduy, luchadora independentista contra la metrópoli española en el Alto Perú; al fundador del positivismo, Augusto Comte, se le rinde culto en iglesias de la Religión de la humanidad en Brasil e incluso en su bandera se inscribió la idea de "orden y progreso" del filósofo galo; o que el Emilio de Rousseau sirviera para fundar una escuela bajo la dirección de Simón Rodríguez, cosa que nunca pasó en Europa. Estos ejemplos, son signos de lo maravilloso de este continente, expresado en lo cotidiano, en lo que está cerca, solo hay que descubrirlo.

También estamos llenos de hechos heroicos como fueron las campañas de Bolívar, San Martín, Hidalgo, que lograron derrotar la escuela militar española, acostumbrada a guerrear por siglos o una revolución cubana socialista, a solo noventa millas de los Estados Unidos, siendo la primera vez que las conquistas del socialismo ocurrían en español, como afirmara Mario Benedetti. América Latina se muestra al mundo como realidad palpable, profunda, en identidad multívoca que solo necesita estudiarla y conocerla para reconocer sus verdaderas esencias. En el ensayo donde tematiza lo real maravilloso en relación a Haití afirmó:

Donde una casa de larguísimos balcones conduce al palacio de cantería habitado antaño por Paulina Bonaparte. Mi encuentro con Paulina Bonaparte, ahí, tan lejos de Córcega, fue, para mí, como una revelación. Vi la posibilidad de establecer ciertos sincronismos posibles, americanos, recurrentes, por encima del tiempo, relacionando esto con aquello, el ayer con el presente. Vi la posibilidad de traer 
ciertas verdades europeas a las latitudes que son nuestras actuando a contrapelo de quienes, viajando contra la trayectoria del sol, quisieron llevar verdades nuestras a donde, hace todavía treinta años, no había capacidad de entendimiento ni de medida para verlos en su justa dimensión, (el subrayado es nuestro). (CARPENTIER, 1984, p. 76)

Portadora de la teoría carpenteriana de lo real maravilloso americano, demuestra el valor de sus ideas y suma nuevos elementos. Está vivamente comprometido con la necesidad de exaltar y dar a conocer realidades del continente similares al resto del mundo, comprende los prodigios americanos, pero a la vez toma conciencia de la complejidad cultural de América Latina.

En el prólogo a El reino de este mundo, escribió una especie de manifiesto. Expresó con énfasis su nueva teoría, nacida del contraste entre el pensamiento europeo sobre la creación y el pensamiento americano, especialmente relacionado con lo fantástico, lo sobrenatural y lo maravilloso: "Aquí lo insólito es cotidiano, siempre fue cotidiano", (CARPENTIER, 1984, p. 122). El mundo de lo real maravilloso americano es visión de la constante lucha entre lo objetivo y lo subjetivo, entre la libertad y la opresión. Es una especie de alter ego de la realidad, en la que podemos encontrar una perpetua búsqueda y el sueño de vivir en libertad.

En mayo de 1975, invitado por la Universidad Central de Venezuela, vuelve Carpentier a visitar la patria de Bolívar a donde no había regresado desde el triunfo de la Revolución Cubana. De estos fructíferos días surgió el libro Razón de ser. En una de las conferencias que constituyen el libro: "Lo barroco y lo real maravilloso" destacó que el mestizaje latinoamericano era una especie de barroquismo real maravilloso. Al respecto señaló:

Tenemos huasos, chinos y bárbaros, gauchos, cholos y guachinangos, negros prietos y gentiles, serranos, calentanos, indígenas, gente de color, blancos porfiados y patas rones, y salta atrás-según Simón Rodríguez-, [...] aportándole cada cual su barroquismo, entroncamos directamente con lo que yo he llamado lo "real maravilloso" (CARPENTIER, 1984, p. 119).

Y acotó aún más, América Latina, "es el teatro del más sensacional encuentro étnico que registran los anales de nuestro planeta", (CARPENTIER, 1993, p. 2). La razón de este criterio está en su concepción de la cultura y el humanismo plural como patrimonio universal, manifestado en otras ocasiones, cuando encuentra similitudes y diferencias en expresiones latinoamericanas con las de culturas de otras regiones. Por eso se ha afirmado que "Todo mestizaje engendra barroquismos, por acumulación y combinación de formas y sentidos diferentes, a veces contrastantes, pero que logran complementarse y provocar, en quien los contempla, una impresión de originalidad, de autenticidad, aunque sean reconocibles los troncos genésicos", (VÁZQUEZ, 2004, p. 144). Todos conforman algo nuevo que es América Latina, en devenir de siglos, conformando nuestra identidad de humanismo plural, es decir, de identidad en la diferencia. 
La identidad cultural latinoamericana permitió, en su caso, exponer, profundizar y sistematizar la concepción de lo real maravilloso americano como concreción de esta. Entendió por tal un concepto que caracteriza lo extraordinario que sobrepasa los límites imaginados más allá de lo común y lo normal en el orden sociocultural, presupone un todo abierto de oposiciones e interacciones articulantes de carácter heurístico como lo bello y lo feo, lo positivo y lo negativo, la imaginación y la reflexión, lo trágico y lo sublime, lo cotidiano y lo extraordinario, la filosofía y la cosmogonía, formas de lo cómico y lo grotesco, lo temporal y atemporal, lo mítico y lo real, lo humano y lo degradante, lo geográfico y las prácticas socioculturales de hombres en diversos contextos. Al centrar lo real maravilloso en Nuestra América, lo real maravilloso americano constituye concreción de identidad cultural.

\section{Referencias}

ARIAS, Salvador. Recopilación de textos sobre Alejo Carpentier. La Habana, Cuba: Serie Valoración Múltiple. Casa de las Américas, 1997.

CAIRO, Ana. La década genésica del intelectual Carpentier (1923-1933) Imán, Anuario, Centro de promoción cultural Alejo Carpentier. Año II/1984-1985 (Vol. I). La Habana: Editorial Letras Cubanas, 1984-85.

CARPENTIER, Alejo. Écue-Yamba-Ó. La Habana: Editorial Arte y Literatura, 1977.

CARPENTIER, Alejo. La música en Cuba. La Habana: Editorial Letras Cubanas, 1979.

CARPENTIER, Alejo. Ensayos. La Habana: Editorial Letras Cubanas, 1984.

CARPENTIER, Alejo. Entrevistas. La Habana: Editorial Letras Cubanas, 1985.

CARPENTIER, Alejo. Conferencias La Habana: Editorial. Letras Cubanas, 1987.

CARPENTIER, Alejo. El reino de este mundo. La Habana: Editorial Pueblo y Educación, 1992.

CARPENTIER, Alejo. Crónicas (Vol. I y II). La Habana: Editorial Arte y Literatura, 1993.

CARPENTIER, Alejo. Lecturas de juventud. En: R. Rodríguez Beltrán (Ed.), Compilación y notas. La Habana. Casa Editora Abril, 2017.

CHIAMPI, Irlemar. El realismo maravilloso. Forma e ideología en la novela hispanoamericana. Caracas, Venezuela: Monte Ávila Editores, 1983.

LÓPEZ BARALT, M. (). Para decir al Otro. Literatura y antropología en Nuestra América. San juan, Puerto Rico: Ediciones Callejón, 2005.

LÓPEZ LEMUS, Virgilio. Lo real maravilloso y la imago esplendorosa. En Centro de promoción cultural Alejo Carpentier (Ed.), Imán, Anuario (Vol. año II/1984-1985). La Habana: Editorial Letras Cubana, 1985.

ORTIZ, Fernando. La transculturación blanca de los tambores de los negros. In F. Ortiz (Ed.), Estudios etnosociológicos, (compilación, prólogo y notas de Isaac Barreal Fernández). La Habana: Editorial de Ciencias Sociales, 1991.

PADURA, Leonardo. Un camino de medio siglo: Carpentier y la narrativa de lo real maravilloso. Editorial Letras Cubanas: La Habana, Cuba, 1994. 
PORTUONDO, José. Prólogo. Alejo Carpentier. Crónicas (Vol. vol. I y II.). La Habana: Editorial Arte y Literatura, 1993.

PUPO, Rigoberto. Filosofía y literatura en Alejo Carpentier. INFOMED. La Habana, 2003.

Rama, Ángel. Los productivos años setenta de Alejo Carpentier (1904-1980). Latín American Research Review, 2010.

ROIG, Arturo Andrés. Pensar la mundialización desde el sur. Conferencia, Universidad de la Republica, Montevideo, Uruguay. Procesos, Revista Ecuatoriana de Historia (18), 127-137, 2001. https://doi.org/10.29078/rp.v1i18.281

VÁZQUEZ, Marlene. Primeros pasos de Alejo Carpentier a través de lo real maravilloso americano. (Trabajo de Diploma), Universidad Central "Marta Abreu" de Las Villas, Santa Clara, 1987.

VÁZQUEZ, Marlene. Martí y Carpentier de la fábula a la historia La Habana: Centro de Estudios Martianos, 2004.

Recebido em: 04/09/2019. Aceito em: 21/01/2020. 